\title{
Seismic Safety Evaluation of Tabriz Historical Citadel using Finite Element and Simplified Kinematic Limit Analyses
}

\author{
Majid Pouraminian $^{1 *}$ and Mahmood Hosseini ${ }^{2}$ \\ 'Department of Civil Engineering, Ramsar Branch, Islamic Azad University, Ramsar, Iran; \\ mpouraminian@iauramsar.ac.ir \\ ${ }^{2}$ Structural Engineering Research Center, International Institute of Earthquake Engineering \\ and Seismology, Tehran, Iran; hosseini@iiees.ac.ir
}

\begin{abstract}
Nowadays, powerful tools such as 3D FEA software are used for different structures analysis; although using this software for seismic safety assessment and strengthening historical masonry buildings have some problems. Complex building geometry, low information about physical properties of materials, insufficient information about composed material of internal parts of the walls, no permission for applying destructive tests on these buildings, connectivity in their body, long analysis time, and finally expensive analysis process are some of the problems for engineers and researchers working professionally on analysis and numerical modelling of historical buildings. Simplified Kinematic Limit Analysis (SKLA) is a powerful method for historical buildings analysis that is recommended for strengthening historical masonry buildings in Italian O.P.C.M. $3431^{12}$ ordinance. Applied roles in this method are based on virtual work. Compared with other methods, less and more accessible information are necessary for modelling and assessment seismic safety analysis. In this paper a research has been about this method capabilities for Tabriz Alisha Citadel seismic safety analysis. The results have been compared with numerical analysis results of ANSYS software and showed that the building doesn't have enough safety in front of the earthquake prone.
\end{abstract}

Keywords: Earthquake Safety, Finite Element Analysis, Historical building, Simplified Kinematic Limit Analysis, Tabriz Alisha citadel

\section{Introduction}

Iran with more than 11000 historical \& monuments constructions is introduced one of the oldest civilizations in the word ${ }^{1}$. Moreover, most of major earthquake in the world is referred to Iran $^{2}$. List of statistically superlative countries), that is a serious threat for historical building that because during these constructions usually seismic loads are not considered. Therefore it is necessary to identify how these buildings behave during natural hazard (earthquake), and also to do necessary actions to strengthening the buildings and even reconstruct them in some cases. East Azerbaijan Province has 3.6 percent of total constructions of Iran, while most of this construction is located in Tabriz city. One of these splendid constructions is historical Tabriz citadel or Arge- Alisha Tabriz is shown in Figure 1. Arge- Alisha Tabriz huge brick construction goes back to Ilkhanid era. Remained Citadel Alisha is a $\mathrm{U}$ shape plan with average 33 meters height, 51.2 meters width, 21.1 meters length. That is a small part of the whole of this historical architecture ${ }^{3}$. Reminded construction facade is illustrated in Figure 2. Arge Tabriz is situated in a city that is a high earthquake prone area. Thus because of different faults in this area and Arge- Alisha's historical \& cultural significance, this safety assessment of this building is unavoidable 4 . Clay bricks, lime mortar, and

*Author for correspondence 


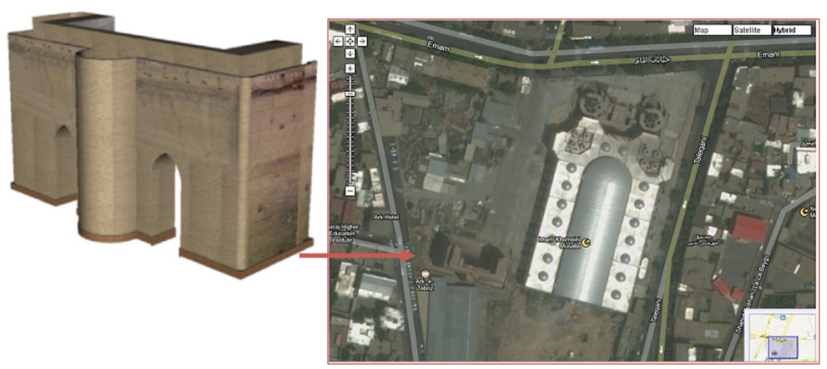

Figure 1. Arial photo of Arge- Alisha Tabriz site.

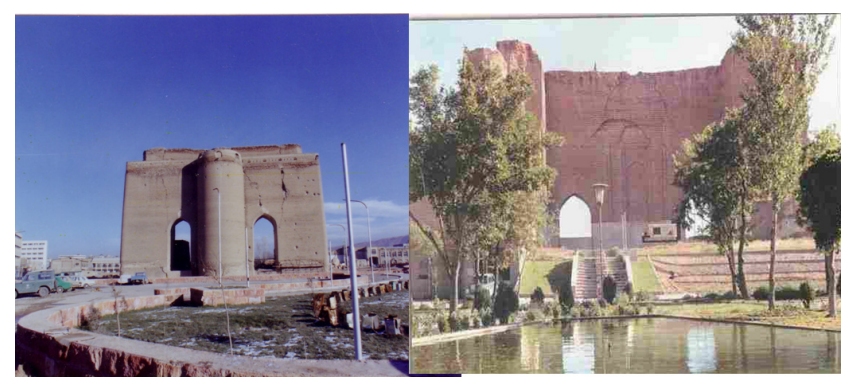

Figure 2. Southern façade of Arge- Tabriz ( right side), northen façade of Arge- Tabriz ( left side).

wood are main materials of these buildings. Clay bricks dimensions are $25^{*} 25$ centimetres with 5.5 thicknesses ${ }^{15}$. Today, all the wooden materials used in the body that are used to tolerate tensile forces are decayed. Betti and Vignoli ${ }^{5}$, used the FEA analysis and compared with that of a simplified approach based on the kinematic theorem of limit analysis for Vicarious Palace in Pescia (Italy). Some recent researches on the seismic assessment of historical constructions by simplified kinematic limit analysis method is done by: (Betti and Galano ${ }^{6}$ ) and (Climent and Pashanejati $\left.{ }^{7}\right)^{16}$.

\section{Simplified Kinematic Limit Analysis}

Historical masonry structures have complex geometry that because of erosion, humidity and their materials mechanical properties has changed a lot. Usually, there is not enough exact information about compose materials of internal parts of the walls. On the other hand, because these constructions are cultural monuments of a country doing destructive tests is against international laws. Therefore producing a numerical model for construction analysis seems difficult, and if applicable solving it by software using FEA programs is time consuming.
SKLA is a powerful method for historical building safety assessment analysis and its usage for retrofitting purpose that is permissible by O.P.C.M. $3431^{12}$ Italian ordinance in both of the linear and nonlinear. In this research linear analysis is used. Because of masonry buildings have rigid box behaviour, often local collapse mechanism (part of structure) is more important than its global collapse mechanism ${ }^{14}$.

To identify probable collapse mechanism, we can use collapse of similar structure in the past earthquakes events. Collapse mechanism in historical masonry building can occur. Either in plane, or out of plane, and out of plane is more common. In Figure 3, Kinematic collapse mechanism and their safety factors that are used in this research is illustrated. Although, we cannot calculate deformation and displacement by limit analysis method. But in many engineering researches determining safety against seismic loads is enough and this method is applicable for huge and complex constructions. While $3 \mathrm{D}$ analysis of complex constructions is not applicable by FEA method, SKLA can determine safety factor $(C=a / g)$ against horizontal loads for various collapse mechanism. Safety factor is considered constant in construction height.

Required data in this method for modelling and safety assessment includes: structure geometry, volumetric weight of structure materials, and compression resistance of materials, design base acceleration and site soil type. One of the most important advantages of this method is no need to destructive and non-destructive tests; moreover, according to O.P.C.M. $3431^{12}$ ordinance and structure materials, we can calculate mechanical properties of materials without any test. In this research according to appendix D tensile strength of masonry is considered $220 \mathrm{~kg} / \mathrm{cm}^{2}$, modulus of elasticity is $2200 \mathrm{~kg} / \mathrm{cm}^{2}$ \& volumetric specific weight of walls material is considered $18 \mathrm{KN} / \mathrm{m}^{3}$.

According to proposed equations in O.P.C.M. $3431^{12}$ ordinance in SKLA, for ultimate limit analysis, safety is provided for each mechanism if equation (1) is satisfied.

$\mathrm{a}_{0}$ : is demand spectral acceleration that activates collapse mechanism. Capacity spectral acceleration is calculated from proposed equations in ordinance.

$\mathrm{a}_{\mathrm{g}}$ : is design acceleration due to the region of building corresponds to the probability by national code, exceeded $10 \%$ in 50 years in relation to gravity acceleration $g$ and it is determined 0.35 for Tabriz city according 

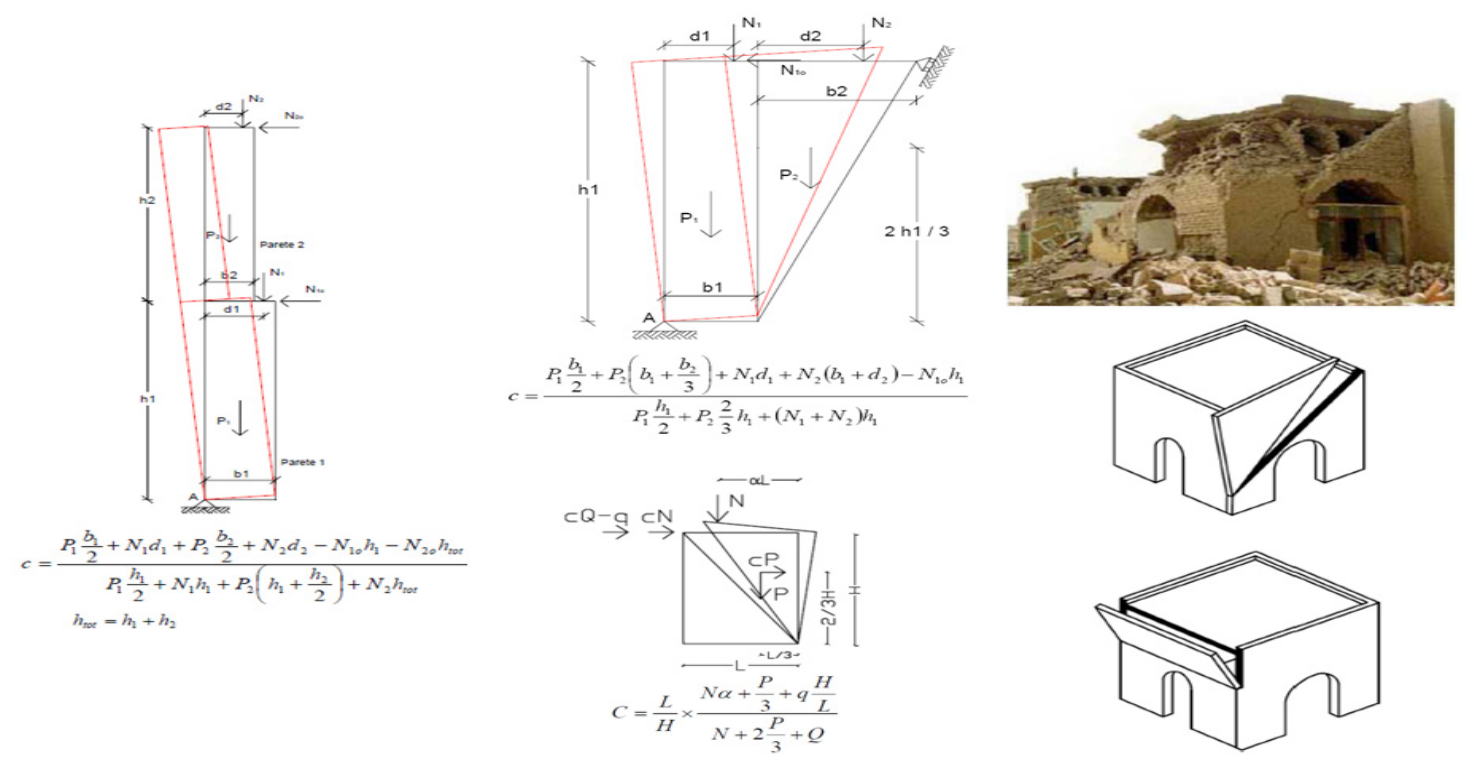

Figure 3. Mechanism of illustration in bam earthquake collapse (right side); safety coefficients equation for various mechanisms (left side).

to national building code (INBC-06 and Standard No2800-84 2005) ${ }^{10,11}$.

S: is soil factor that has different values according to soil type $\&$ is the value of elastic spectrum when natural period $(\mathrm{T})$ is equal to zero.

Z: is the height from the building foundation to the centre of gravity of the weight forces, whose masses generate horizontal forces on the elements of the kinematic chain and which are not efficiently transmitted to the other parts of the building.

$\mathrm{H}$ : is the total height of the building from the foundation q: is the behaviour factor and it is recommended equivalent to 2 according to new Italian ordinance. According to the Instruction for seismic rehabilitation of existing unreinforced masonry buildings ${ }^{8}$, behaviour factor is 1.25. In this research analysis results for both behaviour factors is presented in Table 1.

Equation (1): $a_{0}^{*} \geq \frac{a_{8} S}{q}\left(1+1.5 \frac{Z}{H}\right)$

After SKLA with linear method, Collapse cooficient (C), demand spectral acceleration \& Capacity spectral acceleration is calculated according Table 1. In SKLA, recognizing possible collapse mechanism is the first and the most important step for seismic safety assessment. Table 1 shows that equation (1) reflects that the structure doesn't have enough safety against site capable of seismic loads (for hazard level I). Possible overturning and in plane collapse mechanisms of Tabriz Citadel shown in Figure 4. For M6 \& M7 mechanism, although highest difference is obvious between Demand and Capacity of mechanisms, it reached to its lowest value finally.

\section{Finite Element Analysis}

In order to control seismic verification results from SKLA, the structural behavior of the Palace was investigated using a finite element model in which the non-linearity of the masonry was considered by proper constitutive assumptions. In this research ANSYS software is used for modelling. Mechanical properties of materials are equal for both SKLA \& FEM analysis.

\subsection{Masonry Walls Models}

Currently, there are three strategies to investigate masonry walls behavior by finite element method. These modeling strategies are categorized as a) detailed micro modeling, b) simplified micro modeling and c) macro modelling 9 . In detailed micro modelling strategy, each brick or masonry unit and mortars are modeled separately. In simplified micro modeling method, each masonry unit and half depth of its surrounding mortars is taken as an element. However, in macro modeling the units are neglected and the body of the masonry structure is modeled as a homogenous material. 


\subsection{Structural Model}

Arge Tabriz has about four millions bricks used in its construction and it is not possible to apply micro model strategies to this building, so macro model has been adapted in this research. The major cracks are modeled too that are shown in Figure 5. The code of ANSYS is used to perform linear and nonlinear static and dynamic analyses of the building. In both static and dynamic linear analyses, element Solid45 is selected for modeling the body of the structure. However, for nonlinear static and dynamic analyses element Solid65 is used as the matrix body for nonlinear analyses. Since in threshold of initiation of crack, some numerical instability appears in finite element calculations of this type of elements, to overcome this problem, element Solid95 is used around existing cracks or wherever cracks are expected. Solid95 element is a singular element that resists singularity near tips of cracks. The material physical properties are considered to be, $P=180 \mathrm{C}^{17,18}$.

Static analysis of Arge Tabriz under its own weight shows that the web and both the wing walls are tending inwards that are shown in Figure 6. However, their inward leaning magnitudes are not so large and vary from $7 \mathrm{~mm}$ on the western wing wall to $10 \mathrm{~mm}$ on the web wall. Also static analysis shows that both compression and tension stresses induced by dead load are considerably under permissible ones.

To investigate dynamic characteristics of Arge Tabriz, eigenvalue analysis was carried out with element Solid45.

Table 1. Seismic verification of different failure mechanisms

\begin{tabular}{lccccccc}
\hline Mechanism No. & Wall & Safety Factor & $\mathrm{a}_{0}{ }^{*}$ Capacity & $\mathrm{a}_{0}{ }^{*}$ Demand $(\mathrm{R}=1.25)$ & $\mathrm{a}_{0}{ }^{*}$ Demand $(\mathrm{R}=2)$ & \multicolumn{2}{c}{ Check Structural Safety } \\
\hline M1 & East & 0.348 & 0.43 & 0.66 & 0.41 & $\times$ & $\mathrm{R}=2$ \\
M2 & West & 0.382 & 0.47 & 0.65 & 0.41 & $\times$ & $\checkmark$ \\
M3 & Web & 0.217 & 0.22 & 0.64 & 0.40 & $\times$ & $\times$ \\
M4 & Web & 0.311 & 0.38 & 0.85 & 0.53 & $\times$ & $\times$ \\
M5 & East & 0.254 & 0.12 & 0.76 & 0.48 & $\times$ & $\times$ \\
M6 & West & 0.262 & 0.10 & 0.76 & 0.48 & $\times$ & $\times$ \\
M7 & East & 0.403 & 0.41 & 0.70 & 0.44 & $\times$ & $\times$ \\
M8 & West & 0.433 & 0.439 & 0.70 & 0.44 & $\times$ & $\checkmark$ \\
\hline
\end{tabular}
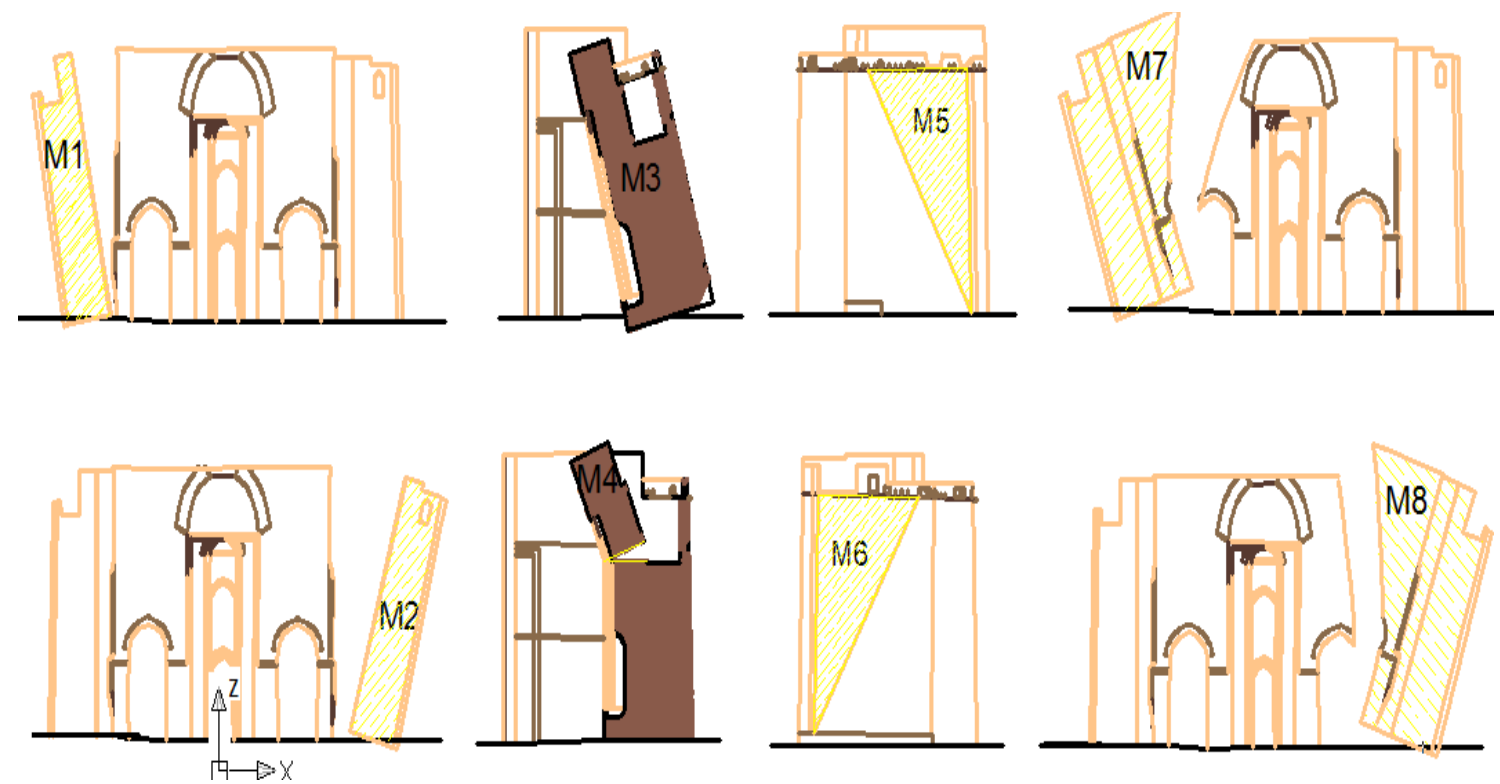

Figure 4. Overturning and in plane collapse mechanisms of Tabriz Citadel. 
The results of eigenvalue analysis showed that in two longitudinal and transverse horizontal directions the main modes are among the few first modes. As another result the most significant modes in both directions were torsional modes as shown in Figure 7. This may be interpreted as the wing walls are not symmetric, so the building is very viable of torsion.

Another eigenvalue analysis of the building was carried out without considering existing cracks. Comparison of the results of two models shows that there is no considerable difference between the periods of the models with crack or without crack that are shown in Figure 8. For the Seismic behavior investigation, series of micro tremor ambient vibration measurements were taken at various locations of the building in the ground, first and second floors by Miyajima et al. that are shown in Figure $9^{13}$ and find that the predominant frequency is $2.6 \mathrm{~Hz}$ in both directions that show good agreement with

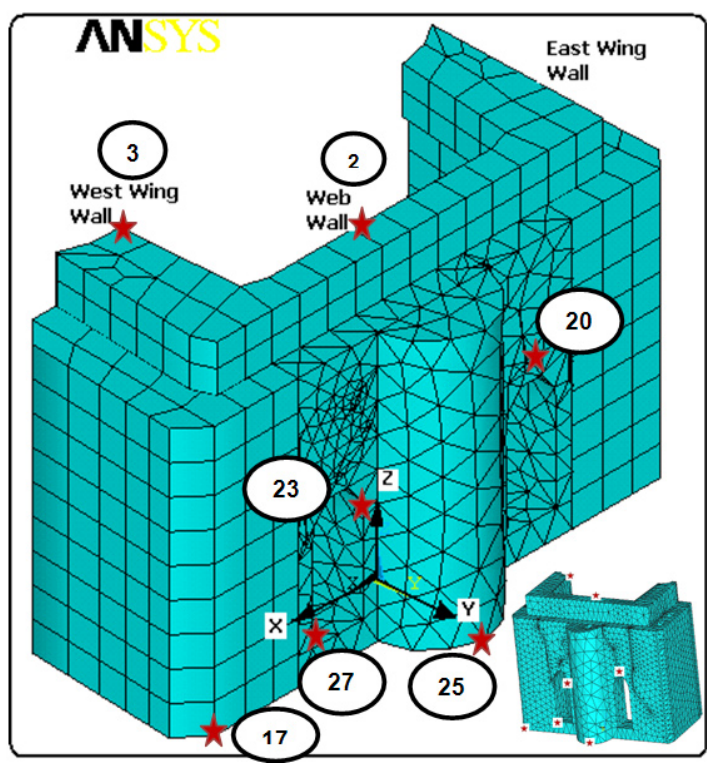

Figure 5. Finite element model of Arge Tabriz.
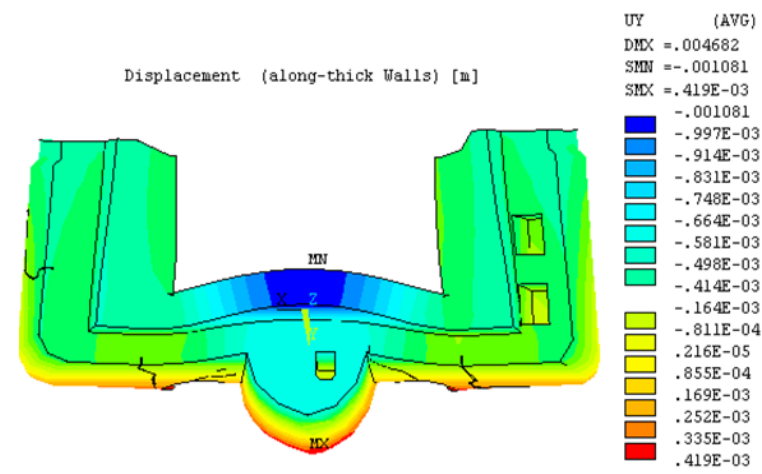

Figure 6. Trend of Walls Deformation under its own weight.
Numerical Model using Ansys Software. This is resulted because of low depth of cracks (depths of cracks are supposed to be between 30 and $90 \mathrm{~cm}$ ) in comparison with the walls thicknesses, i.e. $10 \mathrm{~m}$. In nonlinear analyses, Drucker-Prager yielding criteria was utilized with the material properties of the masonry walls as $\phi=20^{\circ}$ and $\eta=15$ and $c=10^{5} \mathrm{~Pa}$. Also to model crack behavior, William-Warnke criteria was accepted. Following values are taken: $\beta_{t}=0.01, \beta_{c}=0.65, \sigma_{c}=2.2 \mathrm{MPa}$ and $\sigma_{t}=2.2 \mathrm{MPa}$ to satisfy this criteria ${ }^{5}$.

\subsection{Static Nonlinear Analysis}

Static nonlinear analysis usually produces a good view from overall behavior of a structure. So, for both longitudinal and transverse directions, horizontal pushover analyses were performed. Pushover analysis in the direction of the web wall ( $\mathrm{x}$ direction) showed that the structure enters nonlinear phase under a base shear around $20 \mathrm{MN}$ and fails under $30 \mathrm{MN}$. It is worth noting that equivalent static base shear according to Earthquake Loading Code of Practice of Iran (Code 2800), taking a behavior factor $\mathrm{R}=1.25$, is $300 \mathrm{MN}$. It is obvious that the building is very weak against such an enormous natural induced force. The second pushover analysis in the direction of flange walls (y direction) showed even less elastic base shear capacity, namely $20 \mathrm{MN}$. However, this direction showed more ductility, and the same amount of final resistance that are shown in Figures 10 \& 11.

\subsection{Dynamic Linear and Nonlinear Anyalysis}

A recent site investigation supported by Cultural Heritage Organization of Iran (1) has shown that Arge Tabriz is built on an earth type 4 , that is weak soil, with T0 $=1 \mathrm{sec}$. In this regard, from a set of selected strong accelerograms,
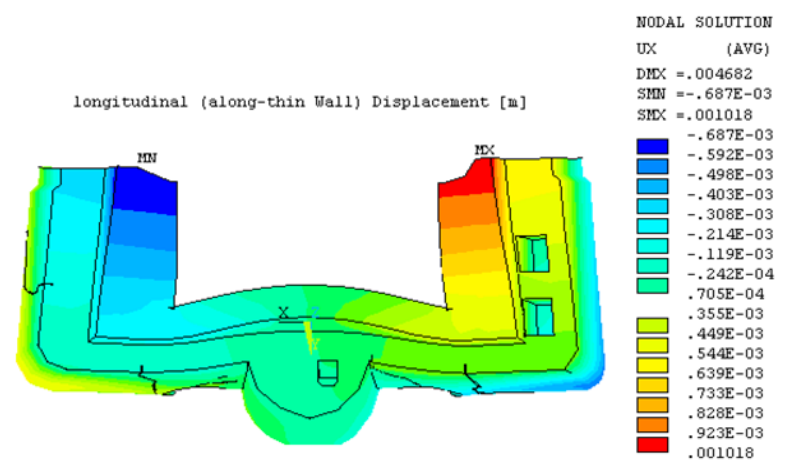
a record of Chi-Chi 1999, Taiwan, in soil type 4 having PGA $=0.3 \mathrm{~g}$ was selected (accelerogram No I) for dynamic analysis. To accommodate the accelerograms to formal regional design spectrum, it was scaled to $0.53 \mathrm{~g}$ (accelerogram No II) following UBC97. Another scaling was performed to achieve $0.64 \mathrm{~g}$ corresponding to Maximum Credible Earthquake (MCE) of Tabriz (accelerogram No III) introduced by Zare and Shahpasand Zade ${ }^{4}$. At first a set of linear dynamic analyses were carried out using the above mentioned three accelerograms. Analyses results showed that under accellerograms No II and No III, compression stress that are shown in Figure 12 exceeds the bearing strength of masonry walls, i.e. 2.2 $\mathrm{MPa}$, for some regions and tension stresses overpass material yield stress, that is $0.2 \mathrm{MPa}$, for some other regions that are shown in Figure 13.

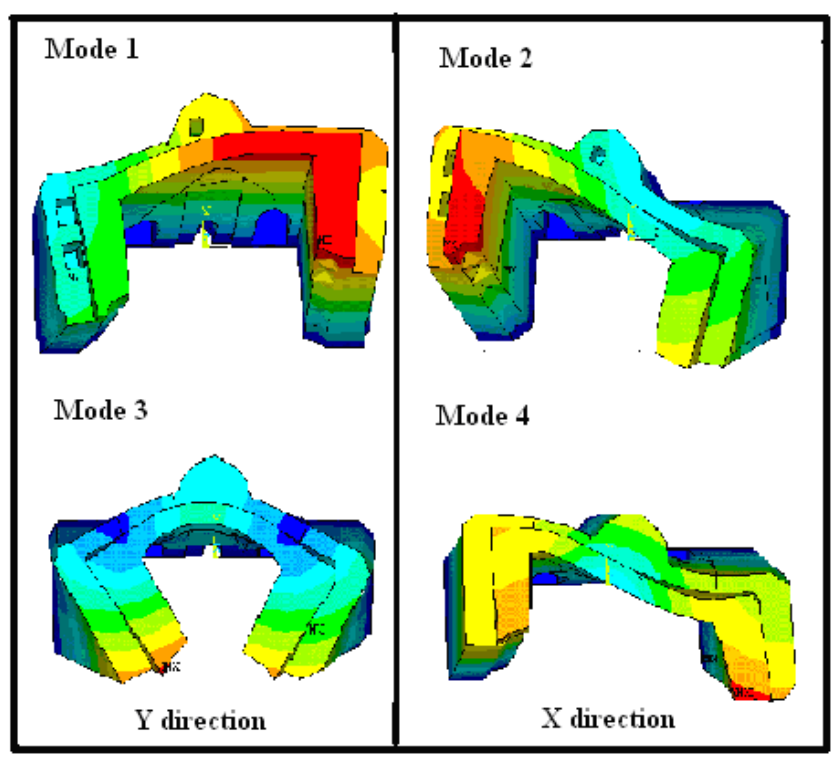

Figure 7. Some effective modes of Arge Tabriz.
To investigate the stress pattern in more rational state, nonlinear dynamic analyses were carried out in two methods:

a) By considering homogeneous nonlinear material behavior

b) By assuming nonlinear material behavior capable of showing cracks

The homogenous nonlinear results showed that displacements of the structure is about two times larger than the the linear analysis results that are shown in Figure 14. Also, compression stresses which in some points were 1.9 $\mathrm{MPa}$ and 2.5 $\mathrm{MPa}$ in linear dynamic analysis under accellerogram No II (PGA $=0.53 \mathrm{~g}$ ), that are shown in Figures 12 \& 15, approached 2.4 MPa and 3.1 MPa in nonlinear dynamic analysis, respectively, where in such stresses the material would crash.

Tension stresses, too, in some points reached 0.7 MPa which is much higher than the material yield stress, namely $0.2 \mathrm{MPa}$. Although this method is not capable of showing potential cracks, but the stress amount implies that some points in the structure will experience cracks that are shown in Figures 16 \& 17 alter.

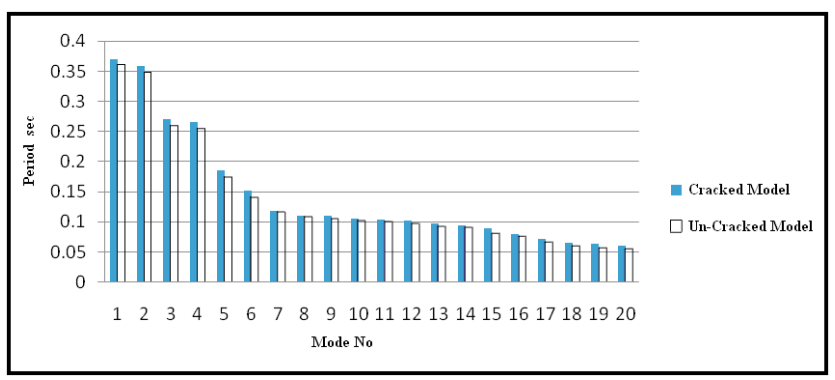

Figure 8. Comparison of cracked and uncracked models.

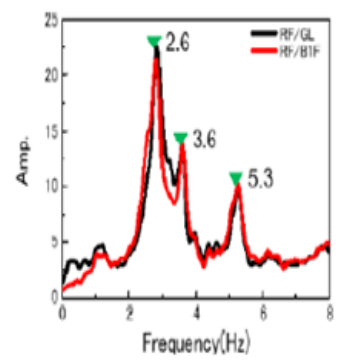

NS direction

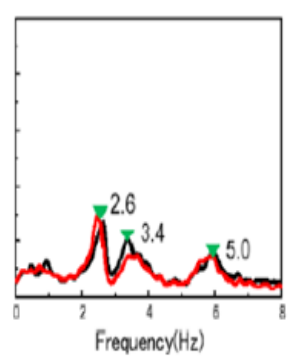

EW direction
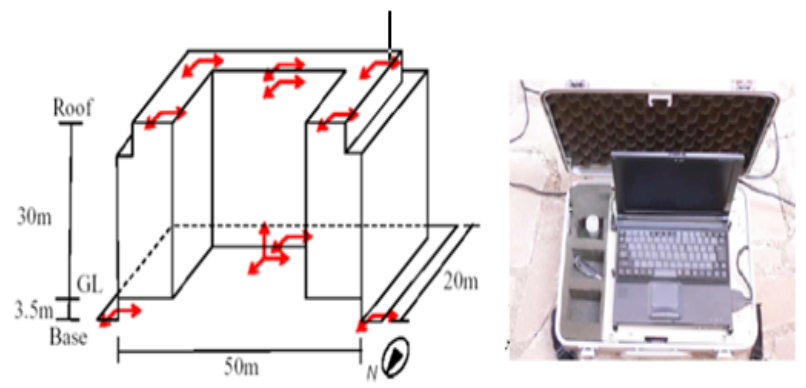

Figure 9. Micro tremor measurements of Arge Tabriz. 


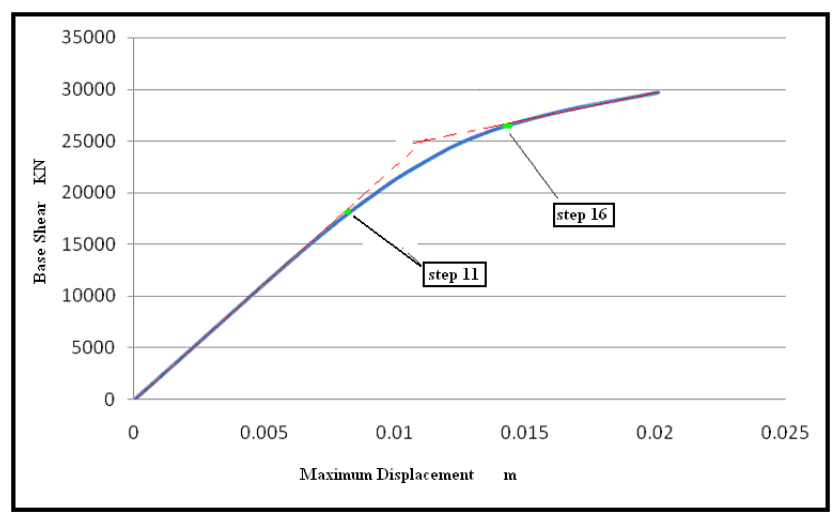

Figure 10. Pushover analysis result of $\mathrm{x}$ direction.

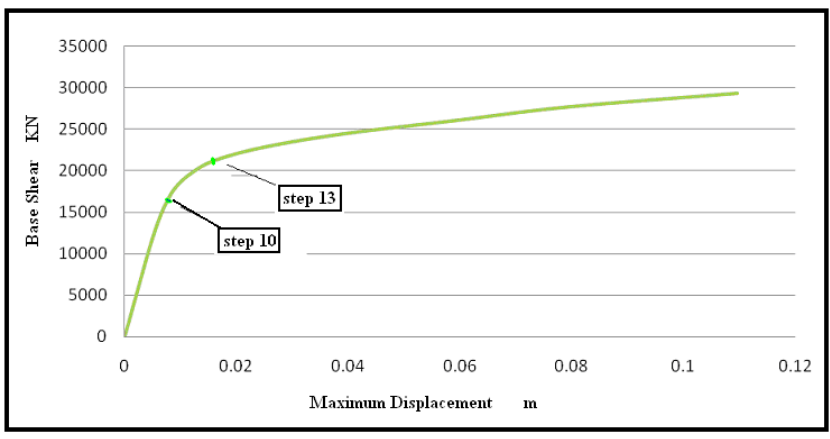

Figure 11. Pushover analysis result of y direction.

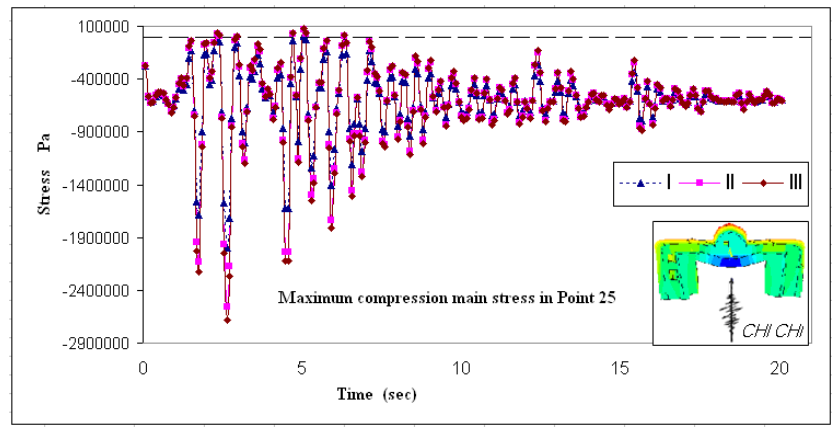

Figure 12. Stress time-history versus scaled No II Chi-Chi accellerogram.

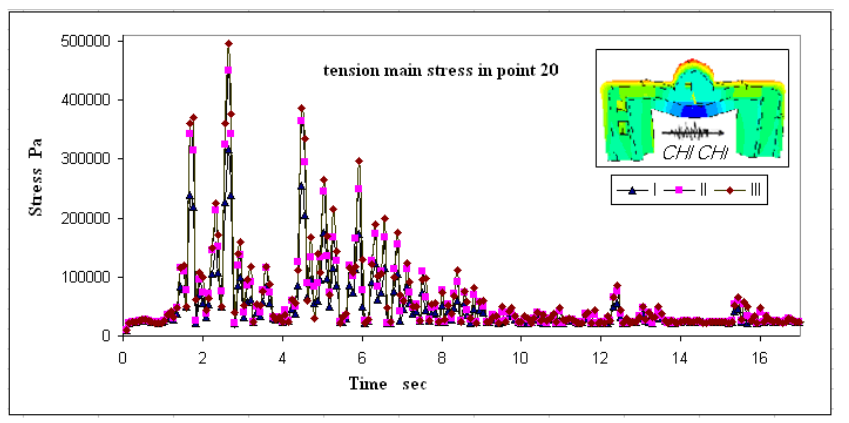

Figure 13. Stress time-history under scaled and unscaled accellerograms.

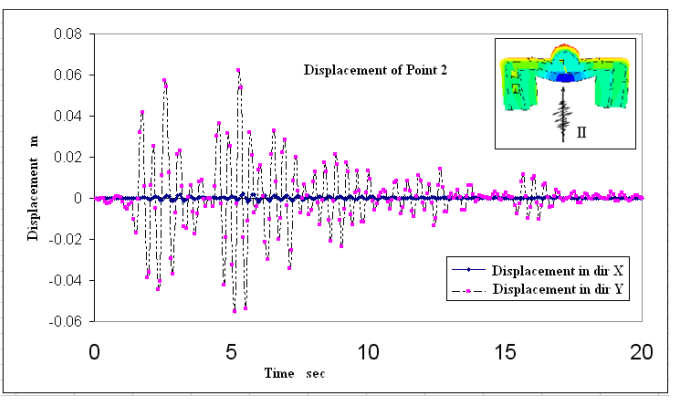

Figure 14. Displacement time-history under No II ChiChi accellerogram.

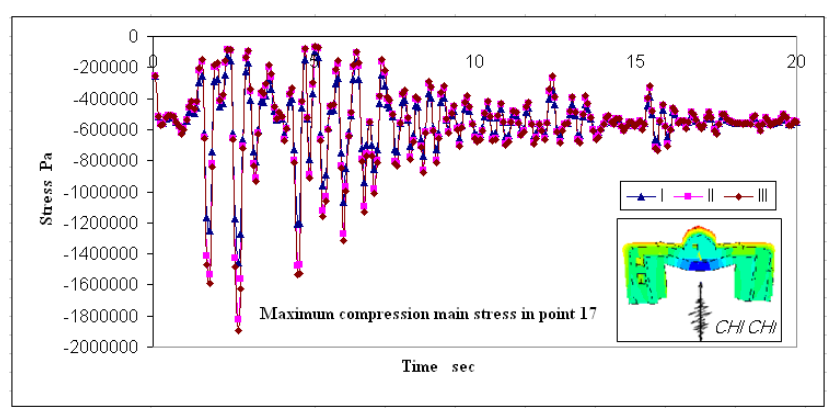

Figure 15. Stress time-history under scaled and unscaled accellerograms.

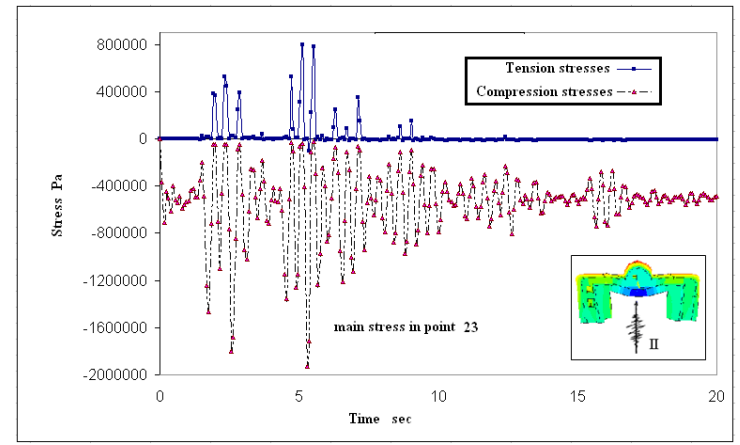

Figure 16. Stress time-history under No II Chi-Chi accellerogram.

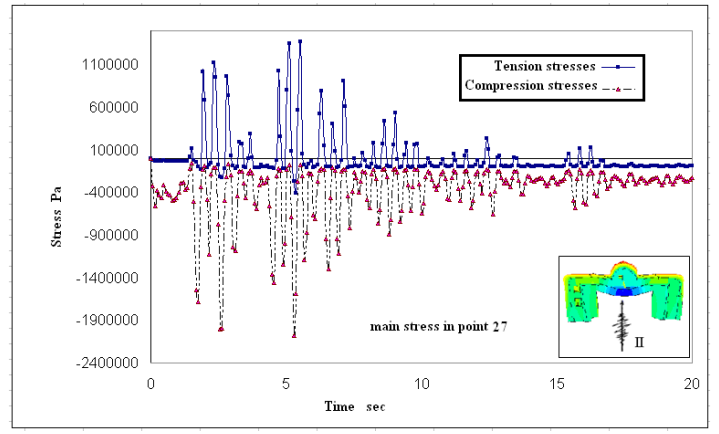

Figure 17. Time-history under No II Chi-Chi accellerogram. 


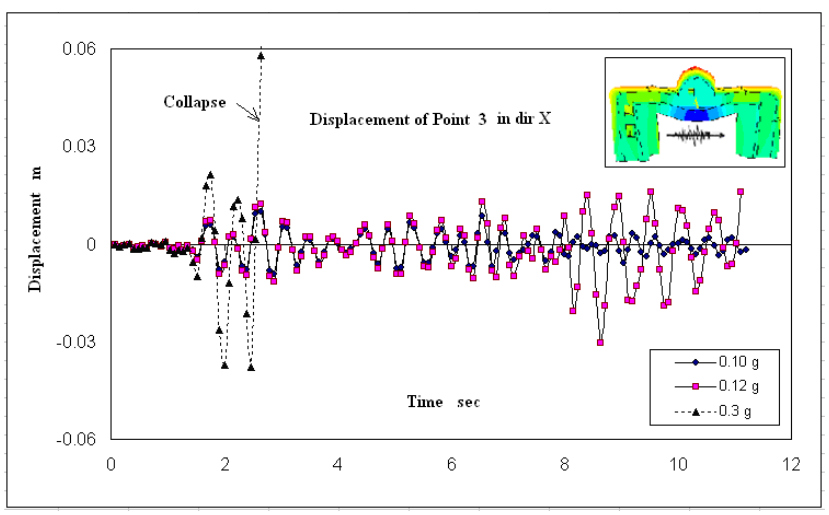

Figure 18. Displacement time-history under Chi-Chi accellerogram.

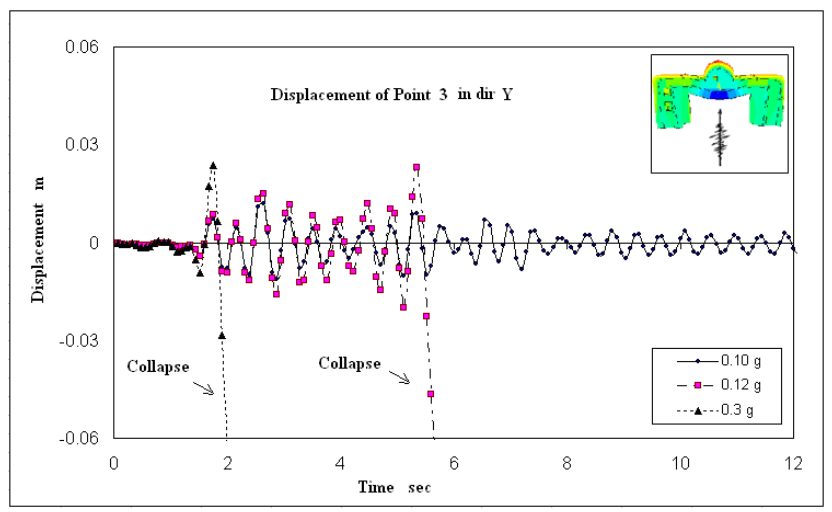

Figure 19. Displacement time-history under Chi-Chi accellerogram.

Nonlinear dynamic analysis by the second method (smeared) is a suitable method to check the possibility of crack appearance. So this method was carried out using capabilities of element Solid 95 of ANSYS. In this case, nonlinearity of material was introduced through William-Warnke criteria. The analysis results indicated that under Chi-Chi earthquake along $\mathrm{x}$ direction that are shown in Figure 18 with scaled PGA $=0.3 \mathrm{~g}$ and along $\mathrm{y}$ direction are shown in Figure 19 with scaled PGA $=0.12 \mathrm{~g}$, the masonry building collapses. More investigation with accellerogram of Erzincan 1992, Turkey, also showed that the structure collapses with scaled PGA $=0.3 \mathrm{~g}$. Erzincan earthquake was selected because it is the nearest record to Tabriz and its source fault is in the same seismic belt. As Figure 20 illustrates, the collapse of the structure is simultaneous with reaching compression stress to $2.2 \mathrm{MPa}$ in point 17.

Summary of nonlinear time response analysis result is presented in the following. The result shows that:

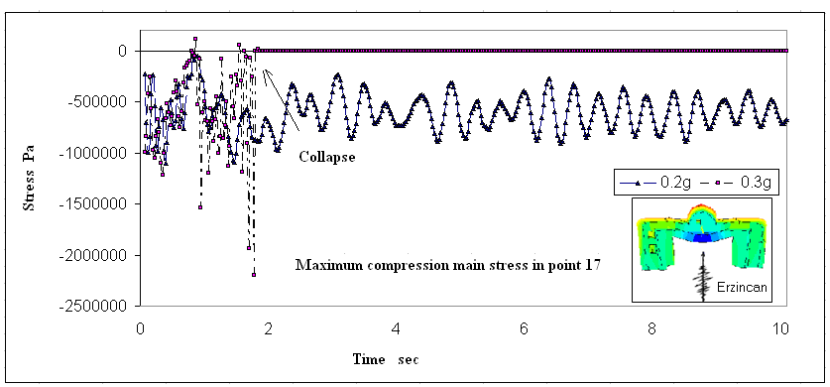

Figure 20. Displacement time-history under Erzincan accellerogram.

1. Arge Tabriz walls show stable up to $0.25 \mathrm{~g}$ for both Chi-Chi (Taiwan, 1999) \& Erzincan (Turkey, 1992) accelerograms. However, the structure loses its stability in $0.3 \mathrm{~g}$ while according to historical documents and recent investigation, the maximum considered earthquake for Tabriz city could be as high as $0.64 \mathrm{~g}$ that is less than required resistance.

2. Dynamic bearing capacity of structure in $Y$ direction is lower than $\mathrm{X}$ direction. Numerous cracks scattered in the web wall, low thickness of web wall, \& two opening in the web wall are some of the weakness reasons in this direction. Coordination axis direction is illustrated in Figures $4 \& 5$.

3. The seismic sensitivity of wing walls is different. Among east, west \& south walls, south wall have the most seismic damage potential. Vulnerability of east wing wall Under $\mathrm{X}$ direction excitation and vulnerability of west wall under $\mathrm{Y}$ direction earthquake excitation are higher. For instance in Figures 18 \& 19, after nonlinear analysis, point(3) displacement response history in the middle of wing walls is shown under Chi-Chi earthquake Horizontal accelerogram with scaled PGAs. (Simulated CHI-CHI earthquake with 10\% exceedense probability in 50 years and soil type (IV) according to Iranian code of practice for seismic resistance design of buildings (Standard No.2800 2005) ${ }^{11}$ and Sadeghi et al. ${ }^{3}$ is calculated $0.53 \mathrm{~g}$.

\section{Conclusions}

Arge Tabriz historical construction is analysed by both SKLA and FEA method. The results show that it doesn't have enough safety against earthquake prone loads in the site. The analysis of both methods is more or less similar. Non-linear time history response analysis results includes: displacement, stresses, wall collapse time, while SKLA only 
used for seismic safety assessment in different mechanisms. This method advantages such as, no need to exact information about materials mechanical properties and any destructive and non-destructive test cause this method to be a powerful tool for evaluating seismic safety of historical buildings especially for huge and complex geometry structures. If we choose behaviour factor of structure 2 based on Italian ordinance, 3 mechanisms will not be active, although capacity and demand of the structure in three mechanisms have close value that indicates getting close to mechanism formation threshold.

\section{Acknowledgement}

The Authors would like to thank Dr. Arjang Sadeghi and Prof. Masakatsu Miyajima from Shahid Madani University of Azerbaijan and Kanazawa University respectively, for their contribution to Numerical Modeling and Micro Tremor Measurements respectively.

\section{References}

1. Available from: http://en.wikipedia.org/wiki/List_of_countries_by_statehood\#Historical_kingdoms_and_dynasties

2. Available from: http://en.wikipedia.org/wiki/List_of_statistically_superlative_countries

3. Sadeghi A, Pouraminian M. An investigation of the vulnerability of Arge Tabriz (Tabriz Citadel). 8th International Masonry Conference; 2010; Dresden, July.

4. Zare M, Shahpasand Zade M. Elementary investigation of seismicity, seism tectonics and seismic risk of East Azarbaijan. International Institute of Seismology and Earthquake Engineering, Tehran; 1995.

5. Betti M, Vignoli A. Assessment of seismic resistance of a basilica-type church under earthquake loading: Modelling and analysis. Adv Eng Software. 2008; 39(4):247-370.

6. Betti M, Galano L. Seismic analysis of historic masonry buildings: the vicarious palace in Pescia (Italy). Buildings. 2012; 2(2):63-82.
7. Climent M, Pashanejati SR. Seismic safety assessment of the Tekyeh Amir Chakhmagh by simplified kinematics limit analysis. Adv Mater Res. 2010; 133-34:653-58.

8. Iranian office of collection and development of national building code (ISRM). Instruction for seismic rehabilitation of existing unreinforced masonry buildings 1st ed; 2006. (In Persian).

9. Mistler M, Butenweg C, Meskouris K. Modelling methods of historic masonry buildings under seismic excitation. Journal of Seismology. 2006; 10(4):497-510.

10. Iranian office of collection and development of national building code (INBC). Iranian national building code, part6: Loading; 1996. (In Persian).

11. Building and Housing Research Center (BHRC). Iranian code of practice for seismic resistance design of buildings (Standard No.2800-84). 3rd ed; 2005. (In Persian).

12. O.P.C.M. 3431/05 09/05/2005. Ulteriori modifiche ed integrazioni all'OPCM 3274/03; 2005. (In Italian)

13. Fallahi AH, Miajima M.Micro Tremor Measurement of Tabriz Historical Building. Bilateral Iran-o-Japan Seminar on Seismology and Earthquake Engineering of Historical Masonry Buildings; 2010 Oct 10-11; Azarbaijan University of Tarbiat Moallem, Tabriz, Iran. p. 4-25.

14. Golabchi M, Homami P, Pashanejati SR. Seismic assessment of the superstructure of the Naghareh Khaneh Edifice after base isolation by simplified kinematic limit analysis. Adv Mater Res. 2010; 133-134, 677:677-82.

15. Hejazi MM. Historical building of Iran, the Architecture and Structure. 1st ed. Southampton; 1997.

16. Roca P. Cervera M, Gariup G, Pela' L. Structural analysis of masonry historical constructions. classical and advanced approaches. Arch Comput Methods Eng. 2010; 17(3):299-325.

17. Pouraminian M, Sadeghi A. Assessment seismic behavior of the historical structures (Case Study: Tabriz Citadel). 1th International Conference on Seismic Retrifitting, Tabriz; 2008 Oct.

18. Pouraminian M, Sadeghi A. (2008). Assessment Seismic Behavior of the Historical Structures (Case Study: Sheikh Shahabe Ahari). 1th International conference on seismic retrifitting, Tabriz, October. 